\title{
Configuration of a pilot station in a technological investigation of groundwater treatment
}

\author{
Pawet Pruss ${ }^{1}$, Alina Pruss, ${ }^{2, *}$, and Matgorzata Komorowska-Kaufman ${ }^{2}$ \\ ${ }^{1}$ AQUA SA, ul. Kanclerska 28, 60-327 Poznan, Poland \\ ${ }^{2}$ Poznan University of Technology, Faculty of Civil and Environmental Engineering, Institute of \\ Environmental Engineering, ul. Berdychowo 4, 60-965 Poznan, Poland
}

\begin{abstract}
The purpose of pre-design technological investigations is to define the water treatment technology for a new or existing water treatment plant. The investigation is performed on model-scale equipment, making sure that the results can be extrapolated to the technological scale. The investigation should allow for the determination of unit process parameters and ensure the desired outcome i.e. treated water meeting the applicable quality standards. Indirectly, the investigation results can also be used as a basis for defining the estimated scope of the investment, the costs of its execution and the future equipment operating costs. Technological investigations are carried out on the grounds of existing or future treatment plants in order to take into account the variable composition and quality indicators of the raw water to be treated. The pilot station, being the main element of the technological investigation, should be designed, built and operated with a view to the possibility of formulating further design guidelines after the study is completed. In this article, the authors share their experience related to the configuration of a pilot station used in an investigation of a groundwater treatment technology.
\end{abstract}

\section{Introduction}

In the light of the changing legal regulations, growing consumer demands and high water production costs, water supply companies which are planning to build or upgrade water treatment plants need effective support to be able to safely decide about the directions of their design and investment activities. The overriding objective is to arrive at the most advantageous water treatment technology from the point of view of the technological processes and cost-effectiveness.

In the case of existing plants, pilot technological investigations are an economical method of testing alternative, often innovative, technologies without interfering with the currently implemented water treatment process. They are useful from the point of view of introducing changes in the existing water treatment process aimed at improvement of the water quality and/or reduction of the production costs. Particularly valuable is the

\footnotetext{
*Corresponding author: alina.pruss@put.poznan.p1
} 
possibility of investigating alternative processes, separately from the processes implemented on the technological scale.

The advantages of using pilot stations include:

- the possibility of testing state-of-the-art technologies and equipment on an ongoing basis,

- a relatively low cost of the investigation versus potential benefits,

- the possibility of performing experiments without disturbing the existing water treatment process,

- no risk of exposing consumers to compromised water quality as a result of the investigation which could happen in the case of full-scale technological investigation involving the operating water treatment plant,

- the possibility to use the investigation results to implement major changes or to optimise the performance of the existing water treatment plant in order to produce highest quality water at minimum costs.

A significant risk, which needs to be considered when deciding about a technological investigation, is the possibility that the obtained results might not be suitable for use e.g. to optimise the existing technological systems.

In some cases, the cost of building the test station might turn out to be too high considering the potential effects, which might warrant resignation from the research.

In this article, the authors present example of technological investigations executed in 2016 to illustrate the steps to be taken in order to select the appropriate configuration of a pilot groundwater treatment plant and the benefits from the performance of a pilot investigation.

\section{Steps to be taken in order to select the appropriate configuration of a pilot groundwater treatment plant}

In general, the design and size of a test station used in a technological investigation depends on the purpose and object of a study, including the characteristics of the investigated processes, systems or equipment [1-12].

The degree of groundwater treatment is determined by the difference between the quality of raw water and the quality parameters it needs to satisfy.

The configuration of the pilot water treatment station will depend directly on the technological processes identified after the quality analysis of the raw water. The selected technological processes, which are presumed to be helpful in the achievement of the objective, should be executed using appropriate model equipment, which will meet the conditions for the projection of the investigation results to the technological scale (such as the height of the model equipment, flow conditions, flow rates, hydraulic load, etc.). An important planning aspect is the location of the station and the layout of the equipment units. The optimum situation is when the test station is situated near the water intake and unrestricted access to all equipment is ensured. When planning the pilot station, attention should also be paid to ensuring appropriate water sampling conditions. Additionally, appropriate space must be dedicated to the performance of ongoing physico-chemical analyses (on-site laboratory).

Before the start of the technological investigation, the analysed water components and quality parameters must be defined and the methods of water sampling and determination has to be specified. It is recommended to distinguish between "working" determinations performed on the ongoing basis by the plant personnel and the "conclusive" determinations performed by an accredited laboratory to evidence the achieved results. 
One of the critical aspects of a well-planned technological investigations is to decide on a sufficient time of the investigation duration. The overall technological investigation period should take into account the time needed for the construction and commissioning of the pilot station, time necessary to analyse the investigated phenomena and time needed to process the results and draw conclusions [13, 14]. In justified cases, the pilot station downtime in order to make corrections or implement modifications warranted by the obtained results and formulated conclusions should also be factored in.

The following sections present a detailed account of the steps to be taken in the case of a technological investigation performed for the purpose of modification of an existing groundwater treatment plant where water from a Quaternary aquifer is treated. In view of the low effectiveness of the processes and equipment in the existing treatment plant, it was assumed that the purpose of the technological investigation was to identify an alternative, more effective water treatment technology with lower operating costs.

\section{Configuration of the pilot station - case study}

\subsection{Analysis of the historical parameters of groundwater quality}

The analysed water intake consisted of five deep wells. According to the quality parameters of the groundwater recorded over a period of a few years, the quality of water from deep well no. 1 differed from the quality of water from the other four wells (no. 2, 3, 4 and 5).

The raw water from all wells was characterised by unacceptable odour (most often characteristic of hydrogen sulphide), $\mathrm{pH}$ close to neutral, intense colour and high turbidity. A constant temperature typical of groundwater was observed. Based on the total hardness value, the raw water from all wells was classified as medium hard. The alkalinity detected in the water meant that it was characterised only by carbonate hardness (the presence of calcium and magnesium bicarbonates).

In the context of the Polish Regulation of the Minister of Health on the quality of water intended for human consumption of 2015 [15] which was in force at the time of the investigation, the non-conformances occurred mainly with regard to such parameters as odour, turbidity and the content of iron and manganese. Moreover, the raw water from the well no. 2 had an increased concentration of ammonia nitrogen, while the water from the well no. 1 additionally demonstrated intense colour and $\operatorname{COD}\left(\mathrm{KMnO}_{4}\right)$.

\subsection{Technological processes}

In the analysed water intake, the well no. 1 had a protective function for the remaining wells and only the water from the wells no. 2, 3, 4 and 5 was actually treated in the existing WTP. Therefore, the well no. 2 was selected for the investigation, as the quality of water from that well was comparable to that of the wells no. 3, 4 and 5 and its location allowed for efficient and uninterrupted supply of water to the pilot station. Based on the results of the analysis of available historical quality data of the raw water, it was proposed to test in the technological investigation a standard non-reagent groundwater treatment technology involving the processes of open-air aeration, sedimentation of suspended solids and filtration. Fig. 1 presents the pilot station diagram. 


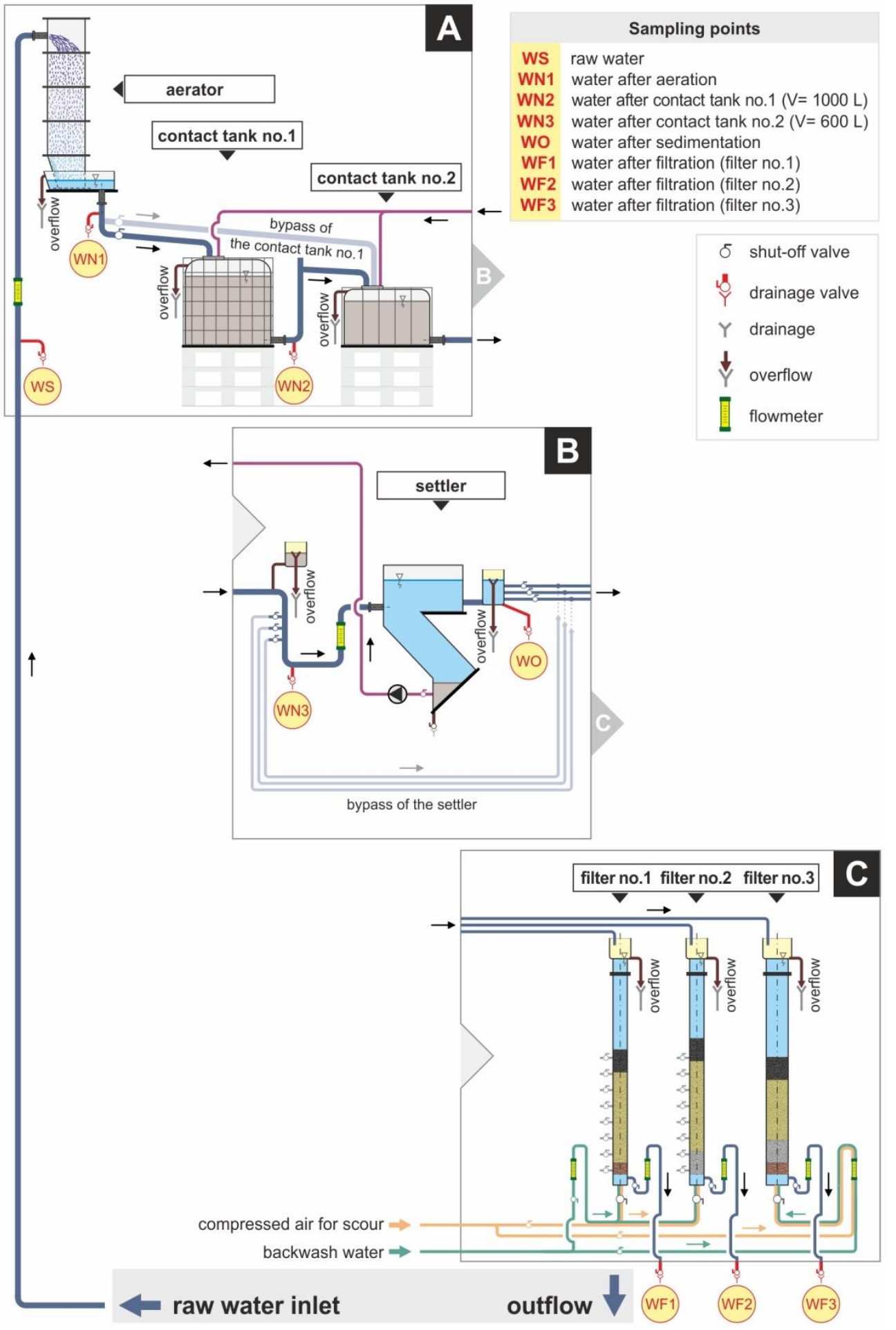

Fig. 1 Configuration of the pilot station. 
The purpose of the water aeration process is to increase the concentration of oxygen in the water. As a result of aeration, the redox potential will grow, the groundwater conditions will change from reducing to oxidising and the carbon dioxide and other gases, such as hydrogen sulphide, will be removed from the water. In effect, the organoleptic properties of the water should improve. The tests should be carried out in the aerator at varying hydraulic loads. In the case under review, due to the characteristics of the raw water, open-air aeration was proposed (exposure of the water to air) with the use of a tank ensuring sufficient reaction time after aeration.

Due to the relatively high iron concentration, it was suggested that the contact tank after aeration should have adjustable capacity and holding time to match the specific oxidation rate for the analysed water. Additionally, a multi-stream settler should be used. Such a configuration was supposed to help identify the optimum contact time of aerated water with dissolved oxygen and allow for partial removal of suspended oxidised iron compounds in the course of the sedimentation process. The lowering of iron concentration in the water by sedimentation results in reduction of the work this contaminant load in the inflow of the rapid filters, which are the next stage of the treatment process. In the investigation, different lamella geometries were used to examine sedimentation effectiveness.

The last element of the pilot station were the rapid filters. In the case of the filtration process, correct execution of the iron removal process across the entire filter bed depth can be expected when the water-air contact time in contact tank will ensure that upon reaching the filter bed, the content of Fe (III) in the water ranges from $30-50 \%$ of the total Fe. The technological investigation was performed using filtration columns filled with various filter beds. During the operation of the filters, filtration parameters (flow rate) and backwashing parameters (backwashing intensity (water), filter bed expansion and backwashing time) were determined.

\subsection{Elements of the pilot station}

The pilot station consisted of the water aerator, two contact tanks, multi-stream settler and three filtration columns. Raw water was supplied to the test station at a rate of 2,800-3,000 $\mathrm{L} / \mathrm{h}$. The flow rate of water supplied to the aerator, the reactors, the settler and the filtration columns was adjusted depending on the needs, using rotameters installed at each of the abovementioned units. Excess water was discharged via overflow outlets.

The water sourced directly from the well was delivered to the pilot station, starting from the first unit of the technological process which was the aerator. The aerator was a $2.5 \mathrm{~m}$ high column made of acid-resistant steel consisting of five segments, in which aerating trays was placed. In order to ensure a gravity flow of the treated water through the pilot station, the aerator was mounted at a high altitude. Raw water entered the aerator through an inlet on the top and passed through all the segments of the unit. In the last, bottom segment, the water flew out through openings in the side wall onto a tray. From there, the aerated and degassed water flew by gravity into the contact tanks.

The contact tanks were standard tanks with the capacity of $1,000 \mathrm{~L}$ and $600 \mathrm{~L}$. In the pilot station, it was possible to use both tanks at the same time, or either of them alone. Such a configuration of the contact tanks allowed for the operation of the entire station with different holding times. It was also possible to bypass one reactor and deliver the aerated water directly to the settler or to the filters (Fig. 1A).

From the contact tanks, the water flew to the settler, or directly to the filters. In the analysed investigation a multi-stream settler made of acid-resistant steel was used. There was a possibility to adjust the flow rate of the water delivered to the settler (within the range of $150 \mathrm{~L} / \mathrm{h}$ to $3000 \mathrm{~L} / \mathrm{h}$ ). The water from the settler outflow chamber was directed to 
rapid filters while the sludge to a sludge hopper. The possibility of sludge discharge or return e.g. to contact tanks was provided for (Fig. 1B).

Three filtration columns were installed in the pilot station. Initially, two filtration columns were used. They were made of polymethylmethacrylate pipes with a diameter of $0.094 \mathrm{~m}$ and a height of $3.0 \mathrm{~m}$ and were equipped with sampling valves for the sampling of water from the whole filter bed and piezometers ensuring continuous measurement of hydrostatic pressure losses. Additionally, rotameters were mounted on outflow from the columns. In order to maintain a constant water head above the filter bed, there were overflows in the upper sections of the filtration columns, so that excess water supplied to the pilot station was discharged into the sewage system, while the predefined flow set at the rotameters was filtered through the bed. The filtration columns were marked off in centimetre units to measure the expansion of the filter bed during backwashing (Fig.1 C). The filtration columns were filled as follows:

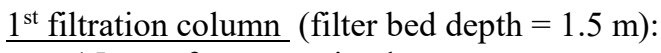

$15 \mathrm{~cm}$ of a supporting layer,

$120 \mathrm{~cm}$ of a quartz sand filter bed $(0.71 \mathrm{~mm}-1.25 \mathrm{~mm}$; WR $<1.5)$,

$30 \mathrm{~cm}$ of an anthracite filter bed $(1.4-2.5 \mathrm{~mm}$; WR $<1.5)$.

$\underline{2^{\text {nd }}}$ filtration column (filter bed depth $=1.5 \mathrm{~m}$ ):

$30 \mathrm{~cm}$ of a manganese removal layer; catalytic mass G-1 $(1.0-3.0 \mathrm{~mm})$,

$120 \mathrm{~cm}$ of a quartz sand filter bed $(0.71 \mathrm{~mm}-1.25 \mathrm{~mm}$; WR $<1.5)$.

Following the analysis of the obtained test results, the content of the filtration columns was modified by adding a $20 \mathrm{~cm}$ deep layer of anthracite in filter no. 1 and a $50 \mathrm{~cm}$ deep layer of anthracite in filter no. 2.

$3^{\text {rd }}$ filtration column had a diameter of $0.2 \mathrm{~m}$ and a height of $4.0 \mathrm{~m}$ and was filled with a $1.0 \mathrm{~m}$ deep filter bed consisting of the following layers:

$15 \mathrm{~cm}$ of a supporting gravel layer,

$30 \mathrm{~cm}$ of a manganese removal layer; catalytic mass G-1 $(1.0-3.0 \mathrm{~mm})$,

$60 \mathrm{~cm}$ of a quartz sand filter bed $(0.71 \mathrm{~mm}-1.25 \mathrm{~mm}$; WR $<1.5)$,

$30 \mathrm{~cm}$ of an anthracite filter bed $(1.4-2.5 \mathrm{~mm}$; WR $<1.5)$.

In the course of the investigation, sand filter bed was added with a grain fraction of $0.1 \mathrm{~mm}$ to $1.25 \mathrm{~mm}$, up to the depth of $80 \mathrm{~cm}$. In the last filtration cycle, the bed was enhanced by adding a $20 \mathrm{~cm}$ layer of quartz sand with a grain size ranging from 0.63 to $1.0 \mathrm{~mm}$.

An impulse for the filter backwashing were pressure losses of $200 \mathrm{~cm}$ or filter bed penetration (presence of $\mathrm{Fe}$ in the filter effluent). The filter bed was scoured by air and backwashed with water, with an intensity ensuring a $30 \%$ filter bed expansion.

\subsection{Methods and scope of the investigation}

The investigation was carried out for a period of six weeks with an aim to identify an effective treatment technology defined in terms of the quality of the raw and treated water. The treated water has to meet the requirements for water intended for the human consumption set forth in the Regulation of the Minister of Health of 13 November 2015 [15] and the relevant EU Directive [16] in force at the time of the investigation.

Additionally, the achievable operating parameters had to be determined, such as:

- the reaction time after aeration

- the filtration rate and hydraulic losses after the filtration process,

- the backwashing intensity, and 
- the filtration bed expansion during the backwashing as a function of the backwashing water flow rate.

The pilot station contained water sampling points. During the pilot tests, continuous water drainage from the sampling valves was ensured to guarantee reliable quality of the collected water samples. Figure 1 presents detailed scheme of the pilot station and shows the points of water sampling for analysis.

The ongoing analytical checks (every 24 hours) included the temperature, $\mathrm{pH}$, alkalinity, acidity, turbidity, colour, odour, dissolved oxygen concentration, redox potential, total and divalent iron, manganese and $\mathrm{COD}\left(\mathrm{KMnO}_{4}\right)$. Additionally, sulphites, chlorides, TOC, ammonia nitrogen, nitrite nitrogen, nitrate nitrogen and total hardness were periodically determined.

Selected parameters of the raw water and treated water is presented in Table 1.

Table 1. Selected parameters of the raw water and treated water.

\begin{tabular}{|c|c|c|c|c|c|c|c|c|c|}
\hline Parameter & Temp & $\mathrm{pH}$ & $\begin{array}{c}\text { Alkali } \\
\text { nity }\end{array}$ & $\mathrm{Fe}$ & Mn & $\begin{array}{c}\text { Turbid } \\
\text { ity }\end{array}$ & Colour & Redox & $\begin{array}{c}\mathrm{COD} \\
\mathrm{KMnO}_{4} \\
\end{array}$ \\
\hline Unit & ${ }^{\circ} \mathrm{C}$ & - & $\begin{array}{c}\text { mval/ } \\
\mathrm{L}\end{array}$ & $\mathrm{mg} / \mathrm{L}$ & $\mathrm{mg} / \mathrm{L}$ & NTU & $\mathrm{mg} \mathrm{Pt} / \mathrm{L}$ & $\mathrm{mV}$ & $\mathrm{mg} \mathrm{O}_{2} / \mathrm{L}$ \\
\hline \multicolumn{10}{|c|}{ Raw water } \\
\hline \multirow{2}{*}{ Range } & 11.0 & 7.04 & 6.33 & 4.00 & 0.07 & 0.74 & 22 & -20 & 3.77 \\
\hline & 12.1 & 7.20 & 7.37 & 9.00 & 0.24 & 2.40 & 38 & -45 & 4.78 \\
\hline $\begin{array}{c}\text { Average } \\
\text { value }\end{array}$ & 11.5 & 7.12 & 6.98 & 4.65 & 0.15 & 1.41 & 27 & -32 & 4.15 \\
\hline $\begin{array}{l}\text { Standard } \\
\text { deviation }\end{array}$ & 0.4 & 0.05 & 0.27 & 1.27 & 0.05 & 0.56 & 6 & 7 & 0.31 \\
\hline \multicolumn{10}{|c|}{ Treated water } \\
\hline \multirow{2}{*}{ Range } & 11.41 & 7.28 & 6.83 & 0.000 & 0.000 & 0.33 & 15.0 & 173 & 2.30 \\
\hline & 1.7 & 7.36 & 7.03 & 0.021 & 0.007 & 0.70 & 17.0 & 198 & 3.50 \\
\hline $\begin{array}{c}\text { Average } \\
\text { value }\end{array}$ & 11.6 & 7.32 & 6.90 & 0.014 & 0.002 & 0.51 & 15.7 & 186 & 3.00 \\
\hline $\begin{array}{l}\text { Standard } \\
\text { deviation }\end{array}$ & 0.2 & 0.04 & 0.10 & 0.012 & 0.004 & 0.19 & 1.2 & 13 & 0.60 \\
\hline
\end{tabular}

The tests were performed in full filtration cycles, interrupted by the backwashing of filters. The duration of the filtration cycle and water backwashing intensity were also parameters which formed part of the research objectives. Every day, the value of hydraulic losses in the water filtration process were read from the piezometers. Furthermore, filter bed expansion was measured as a function of the backwash water flow rate and the optimum backwashing time was determined.

\section{Summary}

In the analysed case, the test station met all the criteria of hydraulic and technological similarity with the technological scale plant to be designed in the future. Therefore, obtaining identical treated water quality both under the pilot and technological conditions was guaranteed.

The investigation ended with the achievement of the expected outcomes. It has been proven that water from well no. 2 can be effectively treated using a technology based on natural aeration and rapid filtration processes. The technological processes were defined and technological guidelines were formulated for designing the water treatment plant. It has been demonstrated that the applied technology will ensure the achievement of water 
quality parameters consistent with the requirements of the applicable regulations, in particular as a result of:

- total removal of $\mathrm{H}_{2} \mathrm{~S}$ and improvement of organoleptic water properties to the level acceptable by consumers,

- total removal of aggressive $\mathrm{CO}_{2}$ in the event of its occurrence in raw water and achievement of chemical water stability according to the calcium carbonate balance criterion,

- reduction of the total iron concentration to a maximum level of $0.2 \mathrm{mg} \mathrm{Fe} / \mathrm{L}$,

- reduction of the total manganese concentration to a maximum level of $0.05 \mathrm{mg} \mathrm{Mn} / \mathrm{L}$,

- reduction of the ammonia nitrogen concentration after the period of nitrifying bacteria growth in the filtration bed [17].

The authors would like to express their thanks for the financial support from industry project 01/13/PRJG/0845 and research project 01/13/DSPB/0857.

\section{References}

1. J. Hu, W. Chu, M. Sui, B. Xu, N. Gao, S. Ding, Chem. Eng. J. 335, 352-361 (2018)

2. T.A. Gad-Allah, M.I. Badawy, A.M. Abdel-Aty, R.K. Ali, H. Saleh, Y. Yoon, M.E.M. Ali, Desalin. Water Treat. 85, 16-24 (2017)

3. S. Zhang, S. Gitungo, L. Axe, J.E. Dyksen, R.F. Raczko, Water Res. 105, 85-96 (2016)

4. A. Pruss, P. Pruss, Ochr. Sr. 1, 25-28 (2016)

5. S. Szerzyna, M. Mołczan, M. Wolska, W. Adamski, J. Wiśniewski, „Pilot investigation as a case of science and industry cooperation," The $8^{\text {th }}$ Eastern European Young Water Professionals. Conference "Leaving the Ivory Tower - Bridging the Gap between Academia, Industry, Services and Public Sector”, Gdańsk, Poland (2016)

6. A. Babatunde, J. Burgess, G. Bertanza, R. Rooney, P. Verlicchi, G. Xu, Water Sci. Technol. 71, 463-467 (2015)

7. A. Pruss, Water Sci. Technol. 71, 638-644 (2015)

8. A. Abeynayaka, C. Visvanathan, S. Khandarith, T. Hashimoto, H. Katayama, Y. Matsui, D.R.I.B. Werellagama, Water Sci. Tech.- W. Sup. 14, 246-254 (2014)

9. R. Bray, Ochr. Sr. 4, 33-37 (2013)

10. M. Mołczan, M. Szlachta, Water Sci. Tech.- W. Sup. 11, 699-710 (2011)

11. D.H. Kim, B.H. Lee, Environ. Eng. Res. 16, 237-242 (2011)

12. C. Hallé, P.M. Huck, S. Peldszus, J. Haberkamp, M. Jekel, Envir. Sci. Tech. 43, 3878-3884 (2009)

13. A. Pruss, P. Pruss: Rola badań technologicznych wody w procesie inwestycyjnym in Aktualne zagadnienia $w$ uzdatnianiu $i$ dystrybucji wody. Vol. 4 (wyd. Politechnika Śląska, Gliwice, Poland), 89-100 (2015)

14. A. Pruss, P. Pruss, Instal 7-8, 62-65 (2016)

15. Regulation of the Minister of Health of 13th November 2015 on the quality of water intended for human consumption (Dz. U. 2015 poz. 1989)

16. Council Directive 98/83/EC on the Quality of Water Intended for Human Consumption. Official Journal L 330 (1998)

17. A. Pruss, Ochr. Sr. 1, 35-39 (2007) 